\title{
Asphyxia and the Occurrences of Perinatal Death in Anutapura General Hospital of Palu in 2018
}

\author{
Rosmala Nur $^{1}$, Nurhaya Suardi Patui ${ }^{1}$, Sitti Radhiah ${ }^{1}$, Sri Rahayu ${ }^{1}$, Elvaria Mantao ${ }^{1}$, \\ Rahma Dwi Larasati ${ }^{1}$, Ulfa Aulia ${ }^{1}$, Gabriella Bamba Ratih Lintin ${ }^{2}$, Hajra Rasmita Ngemba ${ }^{3}$, \\ Syaiful Hendra ${ }^{3}$ \\ ${ }^{1}$ Division of Biostatistics, Population, and Family Planning, Public Health Study Program, Faculty of Public Health, Tadulako University, \\ Palu City, Indonesia \\ ${ }^{2}$ Department Of Medicine, Faculty of Medicine, Tadulako University, Palu City, Indonesia \\ ${ }^{3}$ Department Information Technology, Informatics Engineering Study Program, Faculty of Engineering, Tadulako University, Palu City, \\ Indonesia
}

\section{Email address: \\ Nurrosmala09@gmail.com (R. Nur)}

\section{To cite this article:}

Rosmala Nur, Nurhaya Suardi Patui, Sitti Radhiah, Sri Rahayu, Elvaria Mantao, Rahma Dwi Larasati, Ulfa Aulia, Gabriella Bamba Ratih Lintin, Hajra Rasmita Ngemba, Syaiful Hendra. Asphyxia and the Occurrences of Perinatal Death in Anutapura General Hospital of Palu in 2018. Central African Journal of Public Health. Vol. 5, No. 5, 2019, pp. 185-189. doi: 10.11648/j.cajph.20190505.11

Received: July 4, 2019; Accepted: July 23, 2019; Published: August 10, 2019

\begin{abstract}
Background and objective: Perinatal death is fetal death at 28 weeks of gestation or more and infant mortality in the first 7 days of life. WHO data in 2015 showed that 4.5 million babies died in the first year of life. This study aimed to find out the risk factors for perinatal death at Anutapura General Hospital (RSU) of Palu in 2018. Methods: The method used was observational research with a case control approach. The case subject was mothers who had perinatal death and the control group was mothers of infants who did not experience perinatal death. There were 22 case samples and 88 controls with baby age matching. Sampling was done by simple random sampling technique. Results: Data analysis used odds ratio test with $\alpha=$ $5 \%$. The results showed that Asphyxia $(\mathrm{OR}=3.988$ and $\mathrm{CI}=1.097-14.501)$, Low Birth Weight $(\mathrm{LBW})(\mathrm{OR}=2.100$ and $\mathrm{CI}=$ 0.800-5.510) and Congenital Abnormalities $(\mathrm{OR}=5.190$ and $\mathrm{CI}=3.534-7.623)$. Conclusions: Asphyxia, LBW, and Congenital Abnormalities are risk factors causing perinatal death. Recommendations: The mothers are expected to get early familiarization regarding the signs in pregnancy, increase ANC visits to control maternal and fetal health and pregnancy planning.
\end{abstract}

Keywords: Perinatal Death, Asphyxia, Low Birth Weight, Congenital Abnormalities

\section{Introduction}

Infant mortality is a baby who dies and dies early in $<28$ days of birth. Infant mortality is divided into 2, namely early infant mortality that occurs during the first week of life (0-6 days) and slow infant mortality that occurs in 7-28 days of life. Infant mortality, according to the causes, is divided into endogenous and exogenous. Endogenous infant mortality is caused by factors brought by a child since the birth obtained from the parents or obtained during pregnancy and exogenous infant mortality or post-neonatal death caused by factors related to external environmental influences [1].

According to WHO in 2015, as many as 4.5 million babies died in the first year of life. African countries were one of the highest contributors to infant mortality in the world with 55 per 1,000 live births, while European countries experienced 10 infant mortalities per 1,000 live births. Globally, infant mortality rate declined from 63 per 1,000 live births in 1990 to 32 per1,000 live births in 2015. Infant mortality has decreased from 8.9 million in 1990 to 4.5 million in 2015 . The highest mortality rate was obtained in the African region (63 per 1,000 live births), six times higher than in the European region (10 per 1,000 live births). Research conducted in the United Kingdom in 2013, there were 4,722 cases of perinatal death where there were 3,286 cases of stillbirth and 1,436 cases of early neonatal death. Perinatal death rate obtained was 6 deaths per 1000 live births where 4.2 deaths per 1000 live births in stillbirths and 1.8 per 1000 
live births in early neonatal death [2].

Perinatal mortality in several developing countries, based on the Levels \& Trends Report in Child Mortality in 2012, was 24 per 1,000 live births in Bangladesh, 31 per 1,000 live births in India, 42 per 1,000 live births in Pakistan, 26 per 1,000 live births in Myanmar. While the neonatal mortality rate in Indonesia was 15 per 1000 live births [2].

\section{Research Method}

The type of research conducted was quantitative research with analytical design using the case control study approach, because the case control research was the only relatively inexpensive, easy and fast way to find associations between risk factors and rare diseases.

The population was divided into two, namely the case population and the control population. The case population was all infants who experienced perinatal death in Anutapura General Hospital of Palu in 2018, namely 22 cases, while the control population was all infants who did not experience perinatal death at Anutapura General Hospital of Palu in 2018.

Out of many cases, 22 cases and 88 controls were taken as the samples. The ratio of cases and controls was 1: 4 , so the total sample size was 110 samples.

\section{Results}

Based on research conducted at Anutapura General Hospital (RSU) of Palu, the characteristics of respondents can be seen in the following table.

Based on the table above, the age of the mothers was mostly in the 30 -34 years old-age group, namely41 people (37.3\%), babies aged 28 months to 1 day were as many as 16 babies (60\%), housewiveswere as many as 87 people (79.1\%), and the highest education was senior high school, namely 57 people $(51.8 \%)$.

Table 1. Characteristics of Respondents.

\begin{tabular}{|c|c|c|}
\hline Characteristics & $\mathbf{F}$ & $\%$ \\
\hline \multicolumn{3}{|l|}{ Mother's age } \\
\hline $15-19$ years old & 2 & $1.8 \%$ \\
\hline $20-24$ years old & 24 & $21.8 \%$ \\
\hline $25-29$ years old & 27 & $24.5 \%$ \\
\hline $30-34$ years old & 41 & $37.3 \%$ \\
\hline $35-39$ years old & 9 & $8.2 \%$ \\
\hline$>40$ years old & 7 & $6.4 \%$ \\
\hline Total & 110 & 100 \\
\hline \multicolumn{3}{|l|}{ Baby's Age } \\
\hline 28 weeks- 1 days & 16 & $60 \%$ \\
\hline 2 - 4 days & 15 & $20 \%$ \\
\hline 5 - 7 days & 1 & $4 \%$ \\
\hline Total & 110 & 100.0 \\
\hline \multicolumn{3}{|l|}{ Occupation } \\
\hline Housewife & 87 & 79.1 \\
\hline Government Employee & 10 & 9.1 \\
\hline Private Employee & 4 & 3.6 \\
\hline Entrepreneur/Merchant & 9 & 8.2 \\
\hline Total & 110 & 100.0 \\
\hline \multicolumn{3}{|l|}{ Education } \\
\hline Not Attending School & 14 & 16.4 \\
\hline Elementary School & 18 & 12.7 \\
\hline Junior High School & 10 & 9.1 \\
\hline Senior High School & 57 & 51.8 \\
\hline University Graduate/Diploma & 11 & 10.0 \\
\hline Total & 100 & 100 \\
\hline
\end{tabular}

Risk factors for perinatal death occurring at Anutapura General Hospital (RSU) of Palu in 2018 can be seen in the following table:

Table 2. Risk factors for perinatal death at Anutapura General Hospital of Palu in 2018.

\begin{tabular}{|c|c|c|c|c|c|c|c|}
\hline \multirow{3}{*}{ Variable } & \multicolumn{4}{|c|}{ Perinatal Death } & \multirow{2}{*}{\multicolumn{2}{|c|}{ Total }} & \multirow{3}{*}{ OR (CI $95 \%$ ) } \\
\hline & \multicolumn{2}{|c|}{ Case } & \multicolumn{2}{|c|}{ Control } & & & \\
\hline & n & $\%$ & $\mathbf{n}$ & $\%$ & $\mathbf{N}$ & $\%$ & \\
\hline Asphyxia & 19 & 86.4 & 54 & 61.4 & 73 & 66.4 & 3.988 \\
\hline Without Asphyxia & 3 & 13.6 & 34 & 38.6 & 37 & 33.6 & $(1.097-14.501)$ \\
\hline Total & 22 & 100 & 88 & 100 & 110 & 100 & \\
\hline LBW & 14 & 63.6 & 40 & 45.5 & 54 & 49.09 & 2.100 \\
\hline Without LBW & 8 & 36.4 & 48 & 54.5 & 56 & 50.91 & $(0.800-5.510)$ \\
\hline Congenital Abnormalities & 1 & 4.5 & 0 & 0 & 1 & 0.9 & 5.190 \\
\hline Without Congenital Abnormalities & 21 & 95.5 & 88 & 100 & 109 & 99.1 & $(3.534-7.623)$ \\
\hline Total & 22 & 100 & 88 & 100 & 110 & 100 & \\
\hline
\end{tabular}

The results of the study at the Anutapura General Hospital of Palu showed that 19 infants $(86.4 \%)$ who had perinatal death suffered from asphyxia, compared to 3 infants (13.6\%) who did not suffer from asphyxia. Meanwhile, those who did not experience perinatal death and suffer from asphyxia as many as 54 infant respondents (61.4\%), compared to 34 infants who did not experience asphyxia (38.6\%).

The statistical test performed obtained OR value of 3.9 in 95\% CI 1.097 - 14.501, meaning that infants experiencing asphyxia had a risk of having perinatal death 3.9 times greater than that of infants who did not experience asphyxia.

Babies who experienced perinatal deaths were mostly with LBW $<2500$ grams as many as 14 respondents $(63.6 \%)$ compared to those without LBW $\geq 2500$ grams as many as 8 respondents $(36.4 \%)$, while infants who did not experience perinatal deaths had LBW $<2500$ grams as many as 40 respondents $(45.5 \%)$ compared to those who did not have LBW $\geq 2500$ grams as many as 48 respondents $(54.5 \%)$.

The statistical test obtained OR value of 2.1 in $95 \%$ CI 0.800 - 5.510, meaning that babies with LBW had a risk of 
perinatal death 2.1 times greater than babies without LBW.

There was only 1 baby $(4.5 \%)$ who had congenital abnormalities and perinatal death compared to those who never had congenital abnormalities in pregnancy as many as 21 respondents $(95.5 \%)$, while those who did not experience perinatal death had no congenital abnormalities.

The statistical test obtained OR value of 5.1 in $95 \%$ CI 3,534 - 7,623, meaning that babies who had congenital abnormalities hada risk to experience perinatal death 5.1 times greater than infants who do not have congenital abnormalities.

\section{Discussion}

\subsection{The Risk of Asphyxia to Perinatal Death}

Asphyxia neonatorum is a condition of a newborn baby which cannot breathe spontaneously and regularly within 1 minute after birth. It usually occurs in babies born to mothers with premature birth and late birth. The longer the babies do not get oxygen, the more likely they are to experience severe symptoms. Severe asphyxia symptoms can indicate obstruction, injury or failure in the lungs, heart, brain and kidneys.

In general, there are many factors that can cause asphyxia in newborns, whether the factors coming from the mother, such as older primigravida, bad obstetric history, grand multiparity, gestation period, anemia and maternal disease, premature rupture of the membranes, prolonged labor, narrow pelvis, intrauterineinfection, or thefetus, such as fetal distress, multiple pregnancies, breech position, transverse lie position, birth weight, and factors of the placenta.

The statistical test performed obtained an OR value of 3.9 in $95 \%$ CI 1.097 - 14.501, meaning that infants experiencing asphyxia had a risk of having perinatal death 3.9 times greater than that of the infants without asphyxia.

Study which stated that the main cause of perinatal death was asphyxia neonatorum (12.5/1000) [3]. Another research in Bali, Indonesia, using the case control method on 47 women as the cases and 47 women as the controls found that the presence of Asphyxia neonatorum in infants posed a risk of 2,270 timesgreater to the perinatal mortality than in infants without asphyxia neonatorum [4]. Another research that is in line with this research is asphyxia had a risk of 5.3 times to perinatal death [5].

Similar results were also expressed through the results using the observational study method which said that of 184 infants who experienced perinatal death, it was found that $13.04 \%$ of perinatal deaths were caused by asphyxia neonatorum. Asphyxia also accounted for $34 \%$ of perinatal deaths compared to those without asphyxia neonatorum [6].

This is in line with the research which stated that there was a significant relationship between asphyxia and neonatal death, namely infants with asphyxia will be 7.85 times more likely to experience neonatal death compared to those without asphyxia. The value of $\mathrm{p}=0.001$ and the proportion of infants experiencing asphyxia in the case group (62.07\%) was greater than the control group (17.24\%) [7].

These neonatal asphyxia events also have many causative factors including maternal factors, placental factors, fetal factors, neonatal factors, and labor factors. So, these factors also need to be considered to reduce the incidence of asphyxia neonatorum, which can cause perinatal death. Infants experiencing asphyxia neonatorum are at a higher risk of perinatal death compared to those who do not experience neonatal asphyxia because infants with asphyxia tend to experience a decrease in $\mathrm{O} 2$ pressure in their bodies and an increase of $\mathrm{CO} 2$ pressure which worsen the condition of newborns, where babies look limp, decreasing blood pressure, difficulty breathing, and the heartbeat continues to decline [8]. Therefore babies with asphyxia neonatorum have a high risk of perinatal death.

Asphyxia is a condition where the baby cannot breathe spontaneously and regularly after birth, this is due to a disruption of gas exchange or the transport of oxygen from mother to fetus during pregnancy, labor or immediately after birth. Asphyxia can cause rapid decrease in heart rate, blue baby or paleness and weakening or loss of reflexes. Asphyxia neonatorum is a major contributing factor to high neonatal morbidity and mortality. In developed countries, the incidence of asphyxia was found to be 0.3 to $0.9 \%$ of all live births. Such incidence is higher in developing countries.

\subsection{The Risk of Low Birth Weight (LBW) to Perinatal Death}

Low birth weight (LBW) babies are newborns whose birth weight at birth is less than 2500 grams. LBW often occursdue to complication of the diseasessuffered by the mother during pregnancy, such as anemia during pregnancy, and also the age of the motherduring childbirth that is at risk for health, namely the age of $<20$ years old and $>35$ years old, this is also a trigger for the occurrence of low birth weight at the time of labor. But LBW can also be affected by poor nutritional intake during pregnancy, as well as other complications from the mother where the mother gives birth when the gestational age has not yet entered the age of birth

The statistical test performed obtained an OR value of 2.1 in $95 \%$ CI $0.800-5.510$, meaning that LBW babies hadthe risk of perinatal death 2.1 times greater compared to those who did not experience LBW.

LBW babies had a risk of 13,542 times greater related to infant mortality compared to Normal Birth Weight babies with $\mathrm{p}=0.000$ [9]. LBW had a risk of perinatal death of 8.3 times greater than Normal Birth Weight Babies [10].

The results stated that there was a significant relationship between gestational age $(p=0.000 ;$ OR $=77.055)$, multiple pregnancies $(\mathrm{p}=0.000 ; \mathrm{OR}=21.387)$, eclampsia $(\mathrm{p}=0.002$; $\mathrm{OR}=3.310)$, pre-eclampsia $(\mathrm{p}=0.010 ; \mathrm{OR}=1.836), \mathrm{Hb}$ levels $(\mathrm{p}=0.014 ; \mathrm{OR}=1.668)$ and education $(\mathrm{p}=0.044 ; \mathrm{OR}$ $=1.640$ ) with the incidence of LBW. The high incidence of LBW can affect the quality of human resources in the future, because babies born with LBW can also cause an increased risk of permanent disability, cognitive impairment and other 
chronic health problems in the future [8].

LBW increased the mortality risk of infants with Asphyxia by 4.45 times [11]. Babies with Low Birth Weight (LBW) were more likely to have problems with the system of their body, because the conditions of the body are not stable. One of the effects of LBW is asphyxia in infants which can cause short and long-term effects on infant health [12].

The results of this study are reinforced by the results of other studies which stated that there was a significant relationship between birth weight and neonatal mortality [12, 13]. The value of $p=0.016$ and the proportion of case groupwith LBW $(<2500$ grams) was $41.38 \%$ or higher than the control group, which was $10.3 \%$ [12]. This is also in line with the results of study which stated that the value of $p=$ 0.000 , which found that the proportion of infants with LBW in the case group was $65.6 \%$ or greater than the control group at $3.1 \%$. The relationship between birth weight and neonatal deaths isthat the babies with Birth Weight $<2500$ grams, have a 21 times greater risk of neonatal death compared to babies with Birth Weight $\geq 2500$ grams with the value of $\mathrm{p}=$ $<0.001(\mathrm{OR}=6.9 ; 95 \% \mathrm{CI}=6.9-63.3)$. The survival of a baby born is very closely related to birth weight. This is related to the growth and maturation of organs that are not perfect yet. As a result, babies with low birth weight often experience complications that can cause death [13].

\subsection{The Risk of Congenital Abnormalities to Perinatal Death}

Congenital abnormalities are abnormalities in the structure, function or metabolism of the body found in neonates. Congenital abnormalities are abnormalities in the growth of the structure of the baby arising since the life of the conception of the egg [14].

The statistical test obtained an OR value of 5.1 in $95 \%$ CI 3.534 - 7.623, meaning that babies with congenital abnormalities had a risk of having perinatal death 5.1 times greater than babies without congenital abnormalities.

This study is in line with the study stating that there was an influence between congenital abnormalities and neonatal death, which means that congenital abnormalities hadthe risk for the incidence of neonatal death 2.03 times greater [15]. Likewise with the study which stated that congenital abnormalities had a risk of 2.205 times greater for the occurrence of perinatal death compared to infants without congenital abnormalities with a value of $p=0.006$ [16].

A study stated that there was an influence between congenital abnormalities and neonatal deaths because the condition of infants is weak and immunity formed is not perfect, plus congenital abnormalities always end with operative action. Operative actions carried out without being accompanied by treatments that prioritize sterile principles cause other complications that accompany congenital abnormalities, thus causing infant death [15].

Another research stating that infants with congenital abnormalities had a risk of neonatal death of 4.29 times greater compared to normal infants. The results indicate that there is a relationship between congenital abnormalities of infants with neonatal death. Congenital abnormalities or congenital anomalies are abnormalities seen at birth not due to labor process. Some congenital abnormalities can cause direct death in infants such as anencephaly and anal atresia. As for congenital abnormalities that do not directly cause death but can cause disability are cleft lip, hydrocephalus, meningoencephalocele, clubfoot, phocomelia and so on [17].

Congenital anomalies due to chromosomal abnormalities (down and turner syndrome) and congenital anomalies due to intrauterine infection (causing interference in infants in the form of fetal dysmaturity) so that the fetus is born with a lower body weight or dies in the womb. Congenital abnormalities are abnormalities in the growth of the structure of the baby which arise since the life of the conception of the egg. Babies born with congenital abnormalities, generally, will be born as Low Birth Weight (LBW) Babies or small babies for their pregnancy age. Low Birth Weight Babies with congenital abnormalities that have a weight of about $20 \%$ die in the first week of life [18].

In the results of statistical analysis in this study, it was found that disability events were not related to low birth weight. If there was a disability affecting body weight that did not match with gestational age, it was likely the labor had occurred before the full-term gestational age.

\section{Conclusion}

Asphyxia is a risk factor for the incidence of perinatal death in infants. Other factors causing perinatal death are LBW and congenital abnormalities. Efforts to increase the coverage of high-risk services for pregnant women and counseling about the risks of childbirth, as well asto complete the recording in status cards related to infant mortality and the importance of medical quality in conducting health promotion efforts. It is necessary for the community, especially pregnant women, to do early recognition concerning the signs in pregnancy and increase ANC visits to control maternal and fetal health and to know the factors that can influence the occurrence of perinatal death and to be able to anticipate the occurrence of perinatal death by trying to plan the pregnancy at healthy reproductive age, so that the occurrence of perinatal death due to asphyxia, low birth weight and congenital abnormalities can be avoided.

\section{References}

[1] Ainindya Pasca Rachmadani, Shodikin, M. A. and Cicih Komariah (2018). "Faktor-Faktor Risiko Kematian Bayi Usia 0-28 Hari di RSD dr. Soebandi Kabupaten Jember Risk Factors of Perinatal Death Age 0-28 Days at RSD dr. Soebandi Jember", 4 (2), pp. 60-65.

[2] Wellina R. Simamora, Hermie MM. Tendean, L. M. (2016) "Description of Perinatal Death at RSUP Prof. Dr. R. D. Kandou Manado 2015", Jurnal e-Clinic, 4 (no 2), pp. 1-7. 
[3] Muchemi, O. M., Echoka, E., \& Makokha, A. (2015). Factors associated with low birth weight among neonates born at Olkalou District Hospital, Central Region, Kenya. Pan African Medical Journal, 20 (1).

[4] Kardana, I. M. (2016). Risk factors of perinatal asphyxia in the term newborn at sanglah general hospital, bali-indonesia. Journal Medical, 5 (1) pp. 196-99.

[5] Moura, P. M. S. S., Maestá, I., Rugolo, L. M. S. S., Angulski, L. F. R. B., Caldeira, A. P., Peraçoli, J. C., \& Rudge, M. V. C. (2014). Risk factors for perinatal death in two different levels of care: a case-control study. Reproductive health, 11 (1), 11.

[6] de Souza, A. L. S., de Souza, N. L., de França, D. F., de Oliveira, S. I. M., Araújo, A. K. C., \& Dantas, D. N. A. (2016). Risk factors for perinatal asphyxia in newborns delivered at term. Open Journal of Nursing, 6 (07), 558.

[7] de Almeida, M. F. B., Kawakami, M. D., Moreira, L. M. O., dos Santos, R. M. V., Anchieta, L. M., \& Guinsburg, R. (2017). Early neonatal deaths associated with perinatal asphyxia in infants $\geq 2500 \mathrm{~g}$ in Brazil. Jornal de pediatria, 93 (6), 576-584.

[8] Tjekyan, R. M., \& Zulkarnain, M. (2018). Risk Factors And The Incidence Of Low Birth Weight In Dr. Mohammad Hoesin Palembang Hospital 2014. Jurnal Ilmu Kesehatan Masyarakat, 9 (1), 41-52.

[9] Suparmi, S., Chiera, B., \& Pradono, J. (2016). Low Birth Weights and Risk of Neonatal Mortality in Indonesia. Health Science Journal of Indonesia, 7 (2), 113-117.

[10] Remita Y. K, Bisma M, Hanung P. (2019). Low Birth, Prematurity, and Pre-Eclamsia as Risk Factor of Neonatal Asphyxia", jurnal of Maternal and Child Health, 4 (1), pp. 4954.

[11] Mitao, M., Philemon, R., Obure, J., Mmbaga, B. T., Msuya,
S., \& Mahande, M. J. (2016). Risk factors and adverse perinatal outcome associated with low birth weight in Northern Tanzania: a registry-based retrospective cohort study. Asian pacific journal of Reproduction, 5 (1), 75-79.

[12] Kamala, B. A., Mgaya, A. H., Ngarina, M. M., \& Kidanto, H. L. (2018). Predictors of low birth weight and 24-hour perinatal outcomes at Muhimbili National Hospital in Dar es Salaam, Tanzania: a five-year retrospective analysis of obstetric records. Pan African Medical Journal, 29 (1), 1-13.

[13] Azizah, I., \& Handayani, O. K. (2017). Kematian Neonatal Di Kabupaten Grobogan. HIGEIA (Journal of Public Health Research and Development), 1 (4), 72-85.

[14] Firth, C., Petherick, E., \& Oddie, S. J. (2018). Infant deaths from congenital anomalies: novel use of Child Death Overview Panel data. Archives of disease in childhood, 103 (11), 1027-1032.

[15] Tuchtan, L., Lesieur, E., Bartoli, C., Delteil, C., SardaQuarello, L., Torrents, J.,... \& Gorincour, G. (2018). Diagnosis of congenital abnormalities with post-mortem ultrasound in perinatal death. Diagnostic and interventional imaging, 99 (3), 143-149.

[16] Sierra, M., Rumbo, J., Salazar, A., Sarmiento, K., Suarez, F., \& Zarante, I. (2019). Perinatal mortality associated with congenital defects of the central nervous system in Colombia, 2005-2014. Journal of Community Genetics, 1-7.

[17] Sewell, E. K., \& Keene, S. (2018). Perinatal care of infants with congenital birth defects. Clinics in perinatology, 45 (2), 213-230.

[18] Schneuer, F. J., Bell, J. C., Shand, A. W., Walker, K., Badawi, N., \& Nassar, N. (2019). Five - year survival of infants with major congenital anomalies: a registry based study. Acta Paediatrica. 